Article

\title{
Changes in Skin Elasticity and Firmness Caused by Cosmetic Formulas Elaborated with Essential Oils of Aristeguietia glutinosa (matico) and Ocotea quixos (ishpingo). A Statistical Analysis
}

\author{
Tatiana Mosquera ${ }^{1, *(\mathbb{D})}$, Sebastián Peña 2(D), Priscila Álvarez ${ }^{3}$ and Paco Noriega ${ }^{1(\mathbb{D})}$ \\ 1 Quito Campus, Universidad Politécnica Salesiana, Quito 170525, Ecuador; pnoriega@ups.edu.ec \\ 2 Cuenca Campus, Universidad Católica de Cuenca, Cuenca 010107, Ecuador; jpenap@ucacue.edu.ec \\ 3 Ministry of Public Health, Cuenca 010107, Ecuador; priscila.alvarez@saludzona6.gob.ec \\ * Correspondence: tmosquera@ups.edu.ec
}

Received: 27 October 2020; Accepted: 2 December 2020; Published: 10 December 2020

\begin{abstract}
External factors such as prolonged exposure to solar radiation and environmental pollution accelerate the aging process of the skin, and this process is a challenge for pharmacological science. To counteract the effects of skin photoaging, the cosmetic industry has introduced natural topical products that have proved to be effective in reducing signs of age. In this sense, a statistical analysis was conducted on the changes in the properties of firmness and elasticity of the skin caused by cosmetic formulas (lotion and cream) elaborated with essential oils of Aristeguietia glutinosa (matico) and Ocotea quixos (ishpingo) in which the concentration of the oils in two cosmetic products (lotion and cream) varied to be tested in vivo, through the measurement of elasticity and firmness in three times T1 (0 day), T2 (28 days) and T3 (56 days), and in two age groups according to the Glogau scale (30 to 40 and 41 to 50 years). The results showed positive changes in the values of elasticity and firmness of the skin in the presentation of the lotion whose concentration was $20 \%$ Aristeguietia glutinosa (matico) and $80 \%$ Ocotea quixos (ishpingo), with a minimum application time of 28 days.
\end{abstract}

Keywords: cosmetic formulations; elasticity; firmness; essential oils

\section{Introduction}

UVB radiation causes DNA damage, allowing UVA rays to penetrate into the dermis, significantly increasing the production of reactive oxygen species (ROS) that cause long-term skin damage [1]. The theory of aging considers, on the one hand, the genetic condition of each organism and, on the other, a non-genetic process that includes ROS [2].

Living tissues have a control mechanism to keep ROS in balance, and many antioxidants are used [3] when they are generated in vivo. Antioxidants are used in the dermatological field to minimize the appearance of wrinkles or the hyperpigmentation, as they improve their appearance in a natural way [4]. In this sense, the cosmetic industry is increasingly prone to the development of natural botanical ingredients and polypeptides that give skin improvement properties with a successful effectiveness [5]. Cosmetics with natural ingredients, such as essential oils, are a personal care alternative with a growing trend for the coming years [6].

Essential oils have antibacterial, antifungal, anti-inflammatory and antioxidant capacity, the latter being the possible responsible for an anti-aging cosmetic effect [6]. Aristeguietia glutinosa (matico) and Ocotea quixos (ishpingo) have been selected in this research among the large amount of oils that possess this capacity to regenerate the skin. 
Aristeguietia glutinosa (matico) contains antibacterial, antifungal and antioxidant properties due to the presence of phenolic hydroxyl, and is therefore used in the treatment of multiple diseases by improving peripheral circulation and cholesterol mobilization, which are important agents in skin care [7]. In addition, it is attributed antiseptic, healing, expectorant, anti-inflammatory properties and is widely used for skin protection $[8,9]$.

The antioxidant activity of extract and essential oil of leaves and stems of Ocotea quixos (ishpingo) has been studied using spectrophotometric assays with 2,2-Diphenyl-1-picrylhydrazyl (DPPH), diammonium salt (ABTS), Ferric Reducing/Antioxidant Power (FRAP) and peroxidation lipid- ( $\beta$ carotene-linoleate bleaching), showing its protective and antioxidant activity with values very close to those of the reference control used; 2-terbutyl-hydroxytoluene (BHT), especially with stem extract [10], thanks to the presence of caryophyllene, caryophyllene oxide, humulene and copaene [11], being a non-specific donor of hydrogen or electron atoms, and eliminating $52 \%$ of the radicals [12].

The objective of the research is to conduct a statistical analysis of changes in skin elasticity and firmness caused by cosmetic formulas elaborated with essential oils of Aristeguietia glutinosa (matico) and Ocotea quixos (ishpingo). The cosmetic efficacy was evaluated in an in vivo study in which two cosmetic formulas (lotion and cream) contain a combination of essential oils in different concentrations that were applied to 36 subjects classified into two age groups according to the Glogau scale (30 to 40 and 41 to 50 years).

\section{Materials and Methods}

\subsection{Elaboration of Cosmetic Formulas: Lotion and Cream}

The cosmetic formulas used for this study were a cream that consisted of a homogeneous oil/water $(\mathrm{O} / \mathrm{W})$ emulsion resulting from the mixture of two immiscible phases $(26.7 \%$ oil phase and $73.3 \%$ aqueous phase) which were stabilized with emulsifying agents and a lotion that consisted of a homogeneous water/oil (W/O) with $89.8 \%$ aqueous phase and $10.2 \%$ oily phase. The selection of two cosmetic formulas (lotion and cream) for the present study were based on determining if there is a statistically significant difference in this variable because their absorption capacity and penetration into the skin are different.

In the case of cream, glyceryl stearate and stearic acid are responsible for maintaining the consistency of the product for more than 30 days, time elapsed from the processing to the production of the other batch. The obtained formulation presented the physical properties indicated by [13] where the viscosity was not very high, so that it was not difficult to extract the product from the container, nor to apply it. Table 1 shows the ratio of each component and characteristics.

In order to formulate the cream, the ingredients of the oil phase and the aqueous phase were weighed and heated separately until reaching $70^{\circ} \mathrm{C}$. It was constantly stirred with a glass rod until a homogeneous mixture was formed. Then the oily phase was incorporated into the aqueous phase, stirring at $4500 \mathrm{rpm}$ for $10 \mathrm{~min}$ until an emulsion was formed. It was allowed to cool and when the mixture reached a temperature of $40{ }^{\circ} \mathrm{C}$ the essential oil and the fragrance were incorporated. Subsequently, the $\mathrm{pH}$ of the cream was measured, it should have been between 5.5 to 6.5 . If the values are outside the optimal $\mathrm{pH}$ range, it is regulated with triethanolamine when it is acidic and with citric acid when it is alkaline.

The formula for the lotion obtained was made based on previous research [14,15], describing it as an emulsion with a viscosity low enough to flow under the sole influence of gravity. The procedure to prepare the lotion in the same way as the cream, the only difference is that the aqueous phase is incorporated over the oil phase. Table 2 shows the ratio of each component and its characteristics. 
Table 1. Cosmetic formulation of the cream based on Aristeguietia glutinosa (matico) and Ocotea quixos (ishpingo).

\begin{tabular}{|c|c|c|c|c|}
\hline Commercial Name & Function & \multicolumn{2}{|c|}{ INCI Name * } & Percentage \\
\hline Mineral oil & Emollient & \multicolumn{2}{|c|}{ Paraffinum liquidum } & 3 \\
\hline Glyceryl stearate & Emollient/Emulsifying & \multicolumn{2}{|c|}{ Glyceryl stearate (Cithrol 40 GMS) } & 4 \\
\hline Stearic acid & $\begin{array}{c}\text { Emulsifying/Emulsion } \\
\text { stabilizing }\end{array}$ & \multicolumn{2}{|c|}{ Stearic acid } & 5 \\
\hline Cetyl alcohol & Emollient/Emulsifying & \multicolumn{2}{|c|}{ Cetyl alcohol } & 2.5 \\
\hline Cocoa butter & Emollient & \multicolumn{2}{|c|}{ Theobroma cacao butter } & 2 \\
\hline Crodamol GTCC & Solvent & \multicolumn{2}{|c|}{ Caprylic/Capric triglyceride } & 6 \\
\hline Phenova & Preservative & \multicolumn{2}{|c|}{$\begin{array}{l}\text { Phenoxyethanol, Methylparaben, } \\
\text { Ethylparaben, Propylparaben, } \\
\text { Butylparaben, Isobutylparaben }\end{array}$} & 0.8 \\
\hline Dowsil $^{\text {TM }} 245$ Fluid & Emollient & \multicolumn{2}{|c|}{ Cyclopentasiloxane } & 3 \\
\hline Demineralized water & Solvent & \multicolumn{2}{|c|}{ Aqua } & c. s. p. 100 \\
\hline Essential oil & Active ingredient & Essential oil & $\begin{array}{c}\text { Matico } 80 \% \\
\text { Ishpingo } 20 \% \\
\text { Ishpingo } 80 \% \\
\text { Matico } 20 \%\end{array}$ & $\begin{array}{l}0.32 \\
0.08 \\
0.32 \\
0.08\end{array}$ \\
\hline Fragrance & & \multicolumn{2}{|l|}{ Fragrance } & c. s. p. \\
\hline Triethanolamine ** & Regulator & \multicolumn{2}{|l|}{ TEA } & c. s. p. \\
\hline Citric acid $* *$ & Regulator & \multicolumn{2}{|l|}{ Citric acid } & c. s. p. \\
\hline
\end{tabular}

Table 2. Cosmetic formulation of the lotion based on Aristeguietia glutinosa (matico) and Ocotea quixos (ishpingo).

\begin{tabular}{|c|c|c|c|c|c|}
\hline Commercial Name & Function & \multicolumn{2}{|c|}{ INCI Name * } & \multicolumn{2}{|c|}{ Percentage } \\
\hline Aculyn ${ }^{\mathrm{TM}}$ RM 2051 & $\begin{array}{l}\text { Thickening } \\
\text { agent/emulsifier }\end{array}$ & \multicolumn{2}{|c|}{$\begin{array}{c}\text { Sodium Polyacrylate (and) } \\
\text { Dimethicone (and) } \\
\text { Cyclopentasiloxane (and) } \\
\text { Trideceth-6 (and) PEG/PPG 18/18 } \\
\text { Dimethicone }\end{array}$} & \multicolumn{2}{|c|}{1} \\
\hline Dowsil $^{\text {TM }} 556$ Cosmetic Grade Fluid & Emollient & \multicolumn{2}{|c|}{ Phenyl Trimethicone } & \multicolumn{2}{|c|}{5} \\
\hline Dowsil $^{\mathrm{TM}} 245$ Fluid & Emollient & \multicolumn{2}{|c|}{ Cyclopentasiloxane } & \multicolumn{2}{|c|}{3} \\
\hline Phenova & Preservative & $\begin{array}{l}\text { Phenoxyethan } \\
\text { Ethylparaber } \\
\text { Butylparaben }\end{array}$ & $\begin{array}{l}\text { Methylparaben, } \\
\text { ropylparaben, } \\
\text { obutylparaben }\end{array}$ & \multicolumn{2}{|c|}{0.8} \\
\hline \multirow{3}{*}{ Essential oil } & \multirow{3}{*}{$\begin{array}{c}\text { Active } \\
\text { ingredient }\end{array}$} & \multirow{3}{*}{ Essential oil } & Matico $80 \%$ & 0.32 & \multirow{3}{*}{0.4} \\
\hline & & & Ishpingo $20 \%$ & 0.08 & \\
\hline & & & $\begin{array}{c}\text { Ishpingo } 80 \% \\
\text { Matico } 20 \%\end{array}$ & $\begin{array}{l}0.32 \\
0.08\end{array}$ & \\
\hline Demineralized water & Solvent & \multicolumn{2}{|c|}{ Aqua } & \multicolumn{2}{|c|}{ c. s. p. 100} \\
\hline Fragrance & & \multicolumn{2}{|c|}{ Fragrance } & \multicolumn{2}{|c|}{ c. s. p. } \\
\hline
\end{tabular}

${ }^{*}$ International Nomenclature of Cosmetic Ingredients.

\subsection{Characterization of Cosmetic Formulas: Lotion and Cream}

The characterization of the cosmetic formulas (lotion and cream) consisted in developing organoleptic and physicochemical analyzes to guarantee the quality of the product. In this study, 
the analyzes were about color, odor, texture, $\mathrm{pH}$, density and viscosity under ambient conditions. With the results, it was determined if the cosmetic formulas were suitable for the use of the subjects.

\subsection{Sensory Analysis}

The sensory evaluation was developed with the collaboration of 32 untrained panelists from the Salesian Polytechnic University, classifying them into 4 groups of 8 people each. The panelists received 4 formulations. One of those did not contain essential oils as active and the remaining three did contain the essential oils, at different concentrations $(0.4 \%, 0.6 \%$ and $0.8 \%)$.

For the sensory evaluation, each panelist received four containers with one gram of the formulations with spoons of approximately $0.5 \mathrm{~g}$ for the application to the inside of the right and left forearm. Three moments were evaluated: the aroma when the container is uncovered, the aroma on the skin when it's applied, and finally after 5 min of application.

A 9-point numerical hedonic scale was used to evaluate the acceptance of the panelists with respect to the formulations, considering 1 as the lowest score (I dislike it extremely) and 9 as the highest (I like it extremely). Each panelist evaluated 3 parameters of 4 cosmetic formulas and a total of 384 data was obtained. To alter the order of evaluation of the samples, a random Latin box statistical design was used.

\subsection{Selection of Participants}

The study variables were the type of aging according to the age range (36 to 40 and 41 to 50 years), the formulations (lotion and cream) and the concentrations (20\% matico-80\% ishpingo, 80\% matico-20\% ishpingo and without essential oil). Therefore, 12 treatments were evaluated by triplicate and 36 subjects were needed to test the formulations. The selection of participants in the study was made taking into account the following inclusion and exclusion criteria (see Table 3).

Table 3. Inclusion and exclusion criteria for selecting the participants.

\begin{tabular}{|c|c|}
\hline Inclusion & People Who: \\
\hline & $\begin{array}{l}\text { Are women } \\
\text { Women whose age is from } 35-50 \text { years, mean between aging II and III. } \\
\text { Sign appropriate informed consent to ensure the confidentiality of the subject and the } \\
\text { privacy of her identity. }\end{array}$ \\
\hline \multirow[t]{2}{*}{ Exclusion } & Women Who: \\
\hline & $\begin{array}{l}\text { Have an occupation or perform activities involving the frequent use of chemicals. } \\
\text { Are pregnant or breastfeeding. } \\
\qquad \begin{array}{l}\text { Have solar exposure between } 3 \text { and } 6 \mathrm{~h} \text { a day. } \\
\text { Experience skin reaction after solar exposure. } \\
\text { Do not use sunscreen frequently. } \\
\text { Smoke regularly } \\
\text { Present all medical conditions mentioned. } \\
\text { Use night creams frequently or consistently. } \\
\text { Use medications frequently or consistently. }\end{array}\end{array}$ \\
\hline
\end{tabular}

\subsection{Informed Consent and Ethical Principles}

In the informed consent, all the necessary information about the possible risks, benefits, rights, and obligations related to the participation in the study was clearly explained, considering the option not to participate. The academic object of the research was reported, maintaining the privacy of the people and the confidentiality of the information collected. Subsequently, a consent document was delivered for the subjects to read and sign. 


\subsection{Procedure for Applying Cosmetic Formulas to Subjects}

A standardized procedure related with the application of the cosmetic formulas was described verbally and delivered in a writing to the subjects. The protocol consisted in performing a nighttime facial cleaning before applying the cosmetic formula. Subsequently, $1 \mathrm{~g}$ of the product is placed with a spatula on the back of the hand to distribute evenly with the index finger in the specific areas of the forehead, nose, cheekbones and chin. In order to get a better penetration and absorption of the product, it must be spread from the center outwards and perpendicular to the wrinkle trend.

According to the amount of cosmetic formula provided to each subject, and as a way to verify its application, measurements of the masses of the products were made before and after their application (day 28), confirming their use by decreasing approximately $1 \mathrm{~g}$ per day applied, obtaining a relative value of $10 \mathrm{~g}$ of surplus product with a variation of $\pm 2 \mathrm{~g}$.

\subsection{Elasticity and Firmness of the Skin}

The measures of elasticity and firmness were determined in three times T1 ( 0 day), T2 (28 days) and T3 (56 days) using the Cutometer MPA 580 ${ }^{\circledR}$ (Courage + Khazaka Electronic GmbH, Köln, Alemania) in two age groups based on the type of aging and according to the Glogau scale (30 to 40 and 41 to 50 years). Two types of formulations (lotion and cream) were evaluated in 3 concentrations of essential oils: $20 \%$ matico- $80 \%$ ishpingo, $80 \%$ matico-20\% ishpingo and the last one without essential oil. Considering the interaction between the variables mentioned: Type of aging (2), formulations (2) and concentrations (3), 12 treatments were evaluated by triplicate, and it was necessary to choose 36 subjects to test the formulations. The concentration percentage of essential oils was $0.4 \%$. Besides, it was determined by a sensory preference test applied to 32 voluntary women. For studies intended to quantify the effect of an intervention with regard to mechanical properties is recommend a minimum of 30-40 participants, based on normal distribution of the data sets [14].

\subsection{Statistical Design}

For conducting the statistical analysis of the elasticity and firmness of the skin, the parameters shown in Table 4 were considered.

Table 4. Parameters and description.

\begin{tabular}{cc}
\hline Parameters & Description \\
\hline R0 & $\begin{array}{r}\text { Firmness. Decreased total skin extensibility means that the epidermis opposes greater resistance to } \\
\text { suction deformation. Therefore, the closer the values to } 0 \text { the more firmness. }\end{array}$ \\
\hline R5 & $\begin{array}{r}\text { Net elasticity, ability of the skin to return to its original state after applying suction. As the values } \\
\text { approach more than 1, they are equivalent to a higher elasticity. }\end{array}$ \\
\hline R6 & Viscoelasticity. Lower values represent more elasticity and lower plasticity or turbulence. \\
\hline F0 & Firmness of the skin at the time of suction. As the values get closer to 0, it indicates more elasticity. \\
F1 & $\begin{array}{r}\text { Firmness of the skin during relaxation. As the values get closer to } 0 \text {, it indicates more elasticity. } \\
\text { Viscoelasticity. Lower values represent higher elasticity and lower plasticity or turgidity. }\end{array}$ \\
& $\begin{array}{r}\text { Firmness of the skin at the moment of suction. As the values get closer to 0, it indicates more elasticity. } \\
\text { Firmness of the skin during relaxation. As the values get closer to } 0, \text { it indicates more elasticity }\end{array}$ \\
\hline
\end{tabular}

\subsection{Statistic Analysis}

For this study, 108 observations were obtained as a result of the interaction of 2 cosmetic formulations, 3 concentrations, 2 age ranges, 3 measurement sessions and 3 repetitions. Using the INFOSTAT program, an analysis of variance (ANOVA) was developed under a completely random design where the types of formulations, concentrations and application time interacted with the aging characteristics to identify the differences between the treatments. 


\section{Results and Discussion}

\subsection{Characterization of Cosmetic Formulas: Lotion and Cream}

The cream obtained a $\mathrm{pH}$ of 5.2 a density of $0.9470 \mathrm{~g} / \mathrm{mL}$ and a viscosity of 15,800 cp; with a white color, fragrant smell and texture oily and unaltered. The cream obtained a $\mathrm{pH}$ of 5.2 a density of $0.9470 \mathrm{~g} / \mathrm{mL}$ and a viscosity of $15,800 \mathrm{cp}$; with a white color, fragrant smell and oily texture and unaltered. The lotion obtained a $\mathrm{pH}$ of 5.7 a density of $1.01 \mathrm{~g} / \mathrm{mL}$ and a viscosity of 10,400 cp; with a white color, fragrant smell and seamless texture and unaltered.

\subsection{Sensory Test Analysis}

The results show that there is no statistically significant difference in terms of the cream's smell preference in relation with the different concentrations of essential oils for creams with $20 \%$ matico- $80 \%$ ishpingo, $80 \%$ matico-20\% ishpingo. On the other hand, the smell preference of the lotion shows a statistically significant difference between the lotions 20\% matico-80\% ishpingo, 80\% matico-20\% ishpingo in $\mathrm{T} 1$ when the bottle is uncapped and the olfactory perception after 2 min that the product was applicated on the skin. However, there is no significant difference after having elapsed 5 min (Figure 1). Therefore, it is understood that there is no differentiated preferences.
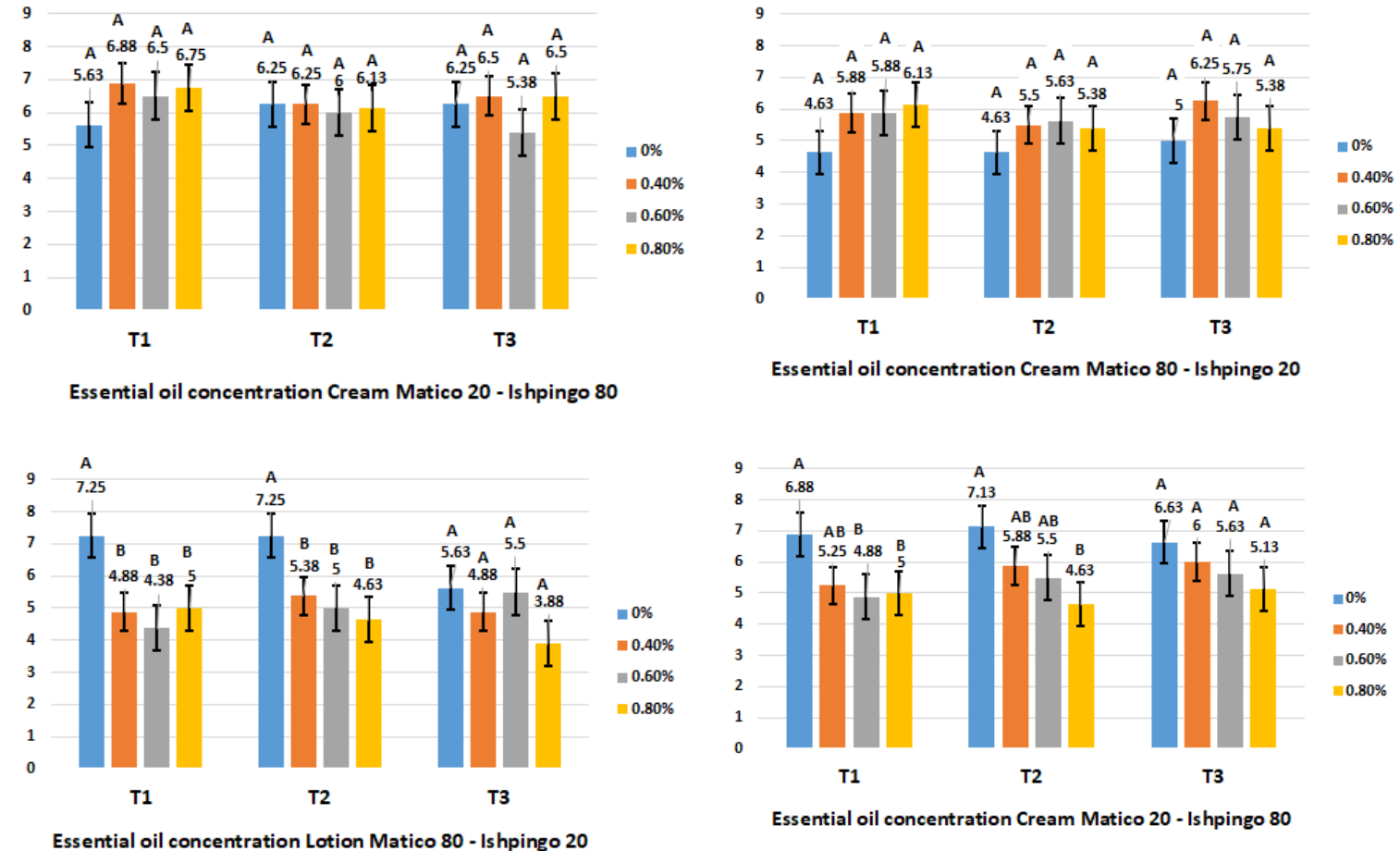

Figure 1. Adjusted means of Sensory test analysis. Note. Two treatments without a common letter are statistically significant $(p \leq 0.05)$.

When evaluating the aroma in both the cream and the lotion, it can be observed that in the cream there is no marked preference for any concentration. This is because the oily consistency of the cream preserves the aroma of the product on the skin for longer. On the contrary, in the lotion a preference for certain concentrations is appreciated. But, as time passed, the tendency disappears, showing in the end that there is no difference between the formulations. In this sense, the lotion is designed so that the active principle remains constantly on the skin after a rapid evaporation of the dispersion medium [16,17].

Due to the fact that a significant difference was found in terms of the smell perception between the percentage of concentration of the essential oils: Aristeguietia glutinosa (matico) and Ocotea quixos 
(ishpingo). The concentration of $0.4 \%$ was chosen for the cream and the lotion because it is the one with the highest valuation after formulations without active ingredient.

\subsection{Skin Elasticity and Viscoelasticity Analysis}

To evaluate changes in skin elasticity and viscoelasticity, a statistical analysis was performed under the completely randomized design in $2 \times 2 \times 3 \times 3$ factorial arrangement performed in the INFOSTAT program of R5 factor (see Figure 2) in relation to sequential hypothesis tests. The variables age, formula and time have statistical significance depending on the $p$ value, since the values are $0.001,0.0284$ and 0.0001 , respectively, considering a confidence level of $95 \%(p \leq 0.05)$. Statistically, dependence is observed for favorable results between age-concentration factors, since when analyzing the interaction of these factors the $p$ value is 0.0001 , and between age-formula-concentration the $p$ value is 0.0095 .
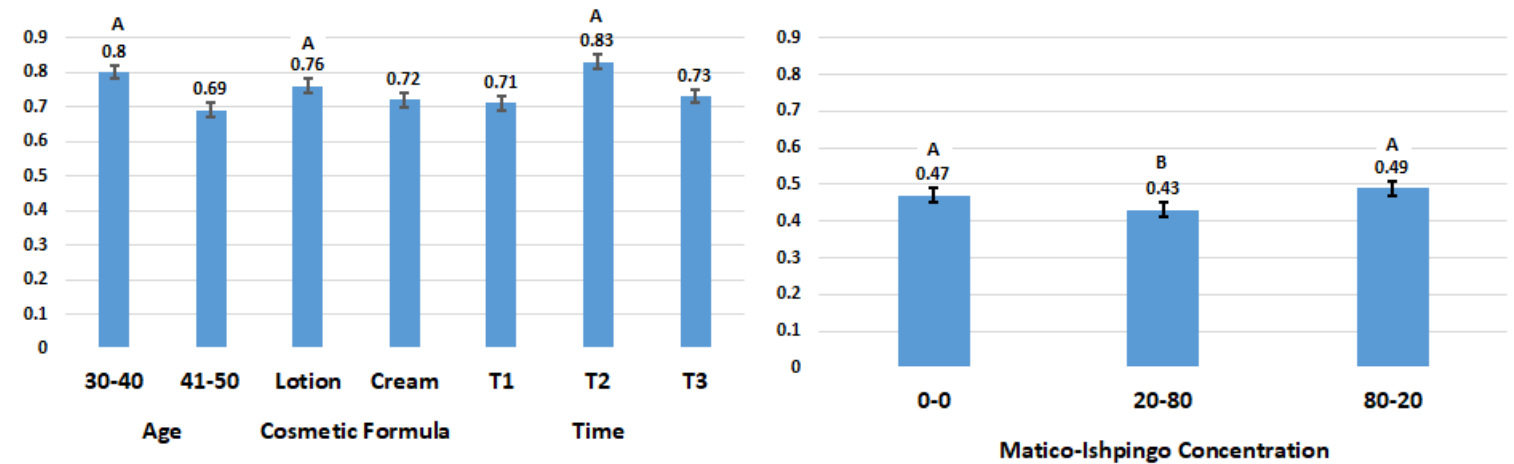

Figure 2. Adjusted means of R5 factors R5 and R6. Note. Two treatments without a common letter are statistically significant $(p \leq 0.05)$.

When performing the adjusted mean and standard errors for age, there is a significant difference in the 30-40 age group, where the mean is 0.80 , considering that values closer to 1 indicate better elasticity. When performing the adjusted mean and standard errors for time, there is a significant difference in time $\mathrm{T} 2$, where the mean is 0.83 , considering that values closer to 1 indicate better elasticity.

In the statistical analysis under the completely randomized design in $2 \times 2 \times 3 \times 3$ factorial arrangement performed in the INFOSTAT program of R6 factor (see Figure 2 in relation to the sequential hypothesis tests, the variable concentration (matico-ishpingo), has statistical significance depending on the $p$ value, since its value is 0.0332 , considering a level of confidence of $99.95 \%(p \leq 0.05)$. When performing the adjusted mean and standard errors for concentration, there is a significant difference for the composition of $20 \%$ matico and $80 \%$ ishpingo, where the mean is 0.43 , considering that values closer to 0 indicate more viscoelasticity.

\subsection{Firmeness Analysis of the Skin}

To evaluate changes in skin firmness, a statistical analysis was performed under the completely randomized design in $2 \times 2 \times 3 \times 3$ factorial arrangement performed in the INFOSTAT program of R0 factor (see Figure 3 in relation to sequential hypothesis tests. The variables formula and time have statistical significance depending on the $p$ value, since the values are 0.0208 and 0.0001 , respectively, considering a $99.95 \%$ confidence level $(p \leq 0.05)$. Statistically, a dependence is observed for favorable results between the formula and time factors, since when analyzing the interaction of these factors the $p$ value is 0.0004 .

There is a significant difference in the lotion when performing the adjusted mean and standard errors for the formula, where the mean is 0.08 , considering that values closer to 0 indicate more firmness. There is a significant difference in time T2 and T3, where the means are 0.07 when performing the adjusted mean and standard errors for time, considering that values closer to 0 indicate more firmness. 
In the statistical analysis under the completely randomized design in $2 \times 2 \times 3 \times 3$ factorial arrangement performed in the INFOSTAT program of F0 factor (see Figure 2 in relation to the sequential hypothesis tests, the variable time has statistical significance depending on the $p$ value, since its value is 0.0001 , considering a confidence level of $99,95 \%(p \leq 0.05)$.

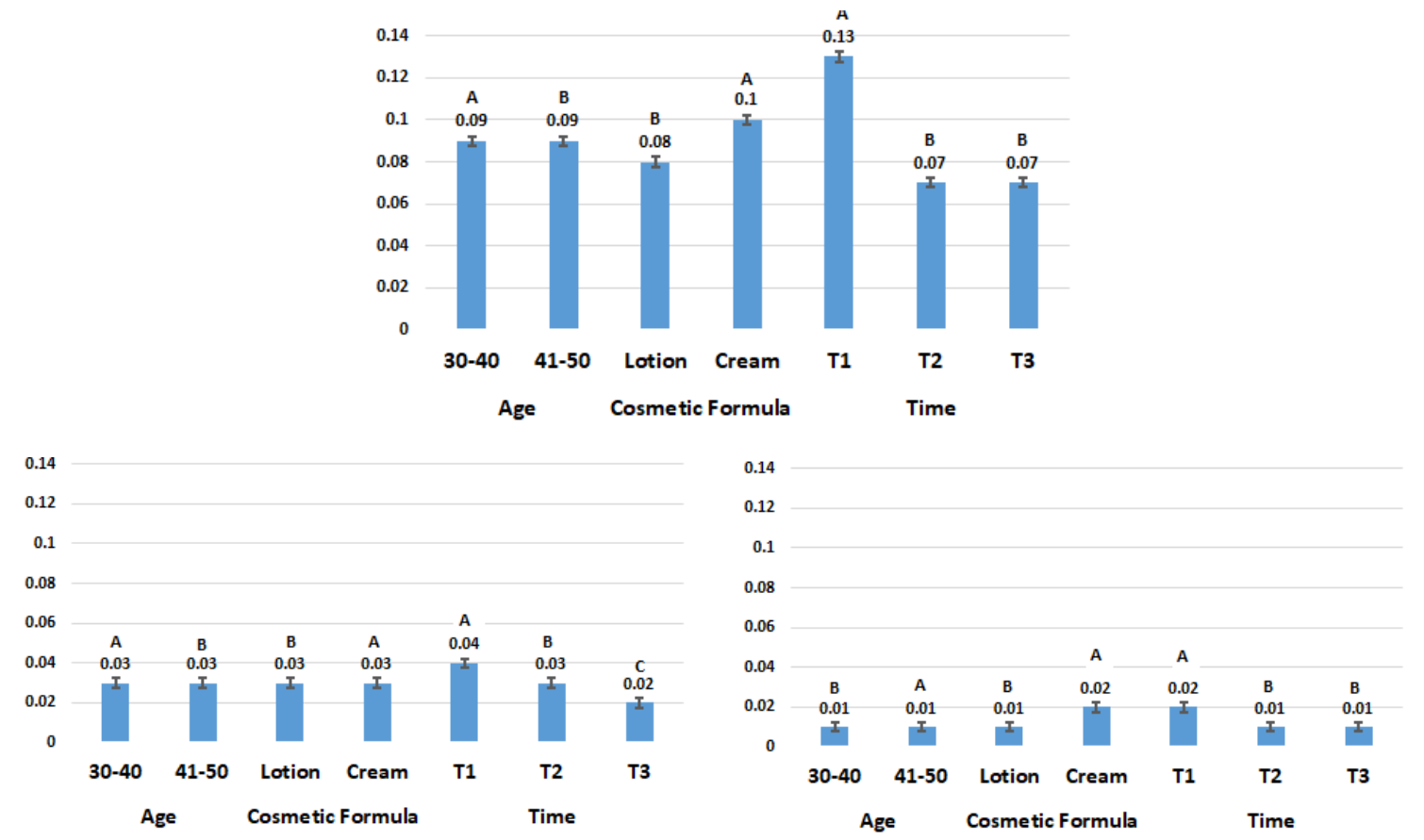

Figure 3. Adjusted means of factors R0, F0 and F1. Note. Two treatments without a common letter are statistically significant $(p \leq 0.05)$.

Although there is no difference between the age, formula and concentration groups individually, statistically there was dependence between the age-formula factors where $p=0.0361$; age-concentration where $p=0.0129$ and between formula-time where $p=0.0012$. There is a significant difference in times T2 and T3 when performing the adjusted mean and standard errors for time, where the mean is 0.03 and 0.02 respectively, considering that values closer to 0 indicate more firmness.

In the statistical analysis under the completely randomized design in $2 \times 2 \times 3 \times 3$ factorial arrangement performed in the INFOSTAT program of F1 factor (see Figure 3 in relation to the sequential hypothesis tests, the variables formula and time have statistical significance depending on the $p$ value, since the values are 0.0063 and 0.0001 respectively, considering a confidence level of $99.95 \%(p \leq 0.05)$. Statistically, a dependency is observed to obtain favorable results between the formula and time factors, because when analyzing their interaction, the $p$ value is 0.0002 .

There is a significant difference in the lotion when performing the adjusted mean and standard errors for formula, where the mean is 0.01 , considering that values closer to 0 indicate more firmness. There is a significant difference in times T2 and T3 when performing the adjusted mean and standard errors for time, where the means are 0.01 , considering that values closer to 0 indicate more firmness.

Studies on the antioxidant activity of essential oils indicate that among the oils with the best antioxidant performance is Ocotea quixos (ishpingo) [12], and in accordance with what was observed in this research by using concentrations of $20 \%$ of matico and $80 \%$ of ishpingo, it was the one which provided the best results.

According to the results obtained with respect to aging (30-40 years), it is evident that there are better results in this age group according to Dobrev [18] who, in similar studies, indicates that there is greater adult skin fatigue than young skin fatigue when relating skin elasticity to age. 
The research conducted by Mosquera et al. [19] tested the cosmetic efficacy of essential oils over time, indicating that after 28 days of treatment, the firmness and elasticity of the skin of subjects have significantly increased. The results shown in Mosquera et al. [19] are consistent with those obtained in this research, where similar changes were observed as the cosmetic formula was applied.

\section{Conclusions}

Following the results of sensory analysis and laboratory tests, a product with suspended particles was obtained in formulations of uniform size, homogeneous and with a pleasant fragrance. The sensory analysis achieved not only to define the formulas with greater acceptance but also to ensure that the study subjects use a product with pleasant organoleptic characteristics.

According to the results obtained, the use of the essential oils of Aristeguietia glutinosa (matico) and Ocotea quixos (ishpingo) as antioxidants in cosmetic formulations improves the elasticity and firmness of the skin in the age group between 30-40 years. This was specifically observed when using the lotion, which contained a concentration of $20 \%$ matico- $80 \%$ ishpingo after 28 days of application. Statistical analysis was performed using factors R5 and R6 for elasticity and R0, F0 and F1 for firmness.

Author Contributions: Conceptualization, T.M. and P.N.; methodology, S.P. and P.Á.; statistic software, S.P.; validation, P.N.; formal analysis, P.N.; investigation, P.Á. and S.P.; resources, T.M. and P.N.; writing original draft preparation, S.P. and P.Á.; writing-review and editing, T.M.; supervision, T.M. All authors have read and agreed to the published version of the manuscript.

Funding: This research received no external funding.

Conflicts of Interest: The authors declare no conflict of interest.

\section{References}

1. Pouillot, A.; Polla, L.; Tacchini, P.; Neequaye, A.; Polla, A.; Polla, B. Natural antioxidants and their effects on the skin. In Formulating, Packaging, and Marketing of Natural Cosmetic Products, 1st ed.; Dayan, N., Lambros, K., Eds.; John Wiley \& Sons, Inc.: Hoboken, NJ, USA, 2011; pp. 239-257.

2. Coronado, M.; Vega y León, S.; Gutiérrez, R.; Marcela, V.; Radilla, C. Antioxidantes: Perspectiva actual para la salud humana. Rev. Chil. Nutr. 2015, 42, 206-212. [CrossRef]

3. De Gálvez, M. Antioxidantes en fotoprotección, ¿realmente funcionan. Actas Dermosifiliogr. 2010, 101, $197-200$. [CrossRef] [PubMed]

4. Abrutyn, E. Antioxidantes en la Prevención de Arrugas. Cosméticos Tecnol. Latinoamérica. 2011, 2, 1-4.

5. Vega, M. Evaluación de la Eficacia del Aceite Esencial de Curcuma Longa L. Como Conservante en una Formulación Cosmética Orgánica. Master's Thesis, Universidad Politécnica Salesiana, Cuenca, Ecuador, 2015.

6. Alcalde, M.T. Cosmética natural y ecológica. Offarm 2008, 27, 96-104.

7. Molina, E. El papel de los antioxidantes como desaceleradores del envejecimiento. Revisión Nutr. Clínica. 2012, 6, 1109-1119.

8. Soto, M. Estudio fitoquímico y cuantificación de flavonoides totales de las hojas de Piper Peltatum L. y Piper Aduncum L. procedentes de la región amazonas. Crescendo. Inst. 2015, 6, 105-116.

9. Buestan, A.; Guaraca, A. Actividad Anti-Inflamatoria de los Extractos de Plantas Medicinales Empleados en el Austro Ecuatoriano en el Modelo de Danio Rerio. Master's Thesis, Universidad de Cuenca, Cuenca, Ecuador, 2013.

10. Naranjo, B.; Braca, A. Composición del aceite esencial de Ambrosia arborescens y sus propiedades. In Etnomedicina y Etnobotánica. Avances en la Investigación, 1st ed.; Naranjo, P., Ed.; Universidad Andina Simón Bolivar/Abya-Yala: Quito, Ecuador, 2010; pp. 199-208.

11. Ortiz, P.; Silva, F.; Galeano, Y. Composición química y actividad biológica de Ocotea quixos. Scientia et Technica. 2012, 7, 110-116.

12. Chasipanta, E.; Chicaiza, T. Evaluación de la Actividad Antioxidante Bioautográfica de 5 Variedades de Aceites Esenciales Amazónicos (Ocotea Quixos; Psidium Guajava; Eugenia Stipitata; Piper Auritum; Piper Imperiale). Master's Thesis, Universidad Politécnica Salesiana, Cuenca, Ecuador, 2016. 
13. Aulton, M. Farmacia: La Ciencia del Diseño de Formas Farmacéuticas, 2nd ed.; Elsevier: Marid, Spain, 2004; pp. 15-41.

14. Wilkinson, J.; Moore, R. Cosmetología de Harry, 1st ed.; Ediciones Díaz de Santos, S.A.: Madrid, Spain, 1990; pp. 57-59.

15. Schvartzman, S.; Cestilli, M. Fórmulas cosméticas de uso corporal. In Dermocosmética. Criterios de formulación. Enfoque estético y Terapéutico, 1st ed.; Schvartzman, S., Cestilli, M.I., Eds.; Editorial; Universidad Católica de Córdoba: Córdoba, Argentina, 2014; pp. 167-174.

16. Monteiro, L.; Fluhr, J. EEMCO Guidance for the in vivo Assessment of Biomechanical Properties of the Human Skin and Its Annexes: Revisiting Instrumentation and Test Modes. Skin Pharmacol. Physiol. 2020, 33, 44-59.

17. Ohshima, H.; Kinoshita, S.; Oyobikawa, M.; Futagawa, M.; Takiwaki, H.; Ishiko, A.; Kanto, H. Use of Cutometer area parameters in evaluating age-related changes in the skin elasticity of the cheek. Skin Res. Technol. 2012, 19, 238-242. [CrossRef]

18. Dobrev, H. Application of Cutometer area parameters for the study of human skin fatigue. Skin Res. Technol. 2005, 11, 120-122. [CrossRef]

19. Mosquera, T.; Noriega, P.; Tapia, W.; Pérez, S. Evaluación de la eficacia cosmética de cremas elaboradas con aceites extraídos de especies vegetales amazónicas: Mauritia flexuosa (MORETE), Plukenetia volubilis (SACHA INCHI) Y Oenocarpus bataua (UNGURAHUA). La Granja. Rev. Ciencias La Vida. 2012, 16, 14-22. [CrossRef]

Publisher's Note: MDPI stays neutral with regard to jurisdictional claims in published maps and institutional affiliations.

(C) 2020 by the authors. Licensee MDPI, Basel, Switzerland. This article is an open access article distributed under the terms and conditions of the Creative Commons Attribution (CC BY) license (http://creativecommons.org/licenses/by/4.0/). 